\title{
Análise da sustentabilidade do turismo: um estudo em comunidades indígenas no Estado de Roraima, Brasil
}

\author{
Analysis of the sustainability of tourism: a study in indigenous communi- \\ ties of Roraima state, Brazil
}

\section{El análisis de la sostenibilidad del turismo: Un estudio en las comunidades indígenas del Estado Roraima, Brazil}

\section{Cristiane do Nascimento Brandão ${ }^{1}$ José Carlos Barbieri² Edgar Reyes Junior ${ }^{3}$}

\begin{abstract}
Resumo: A presente pesquisa foi realizada em três comunidades indígenas do estado de Roraima, que encontraram no turismo uma alternativa para o desenvolvimento local sustentável. Dado que esta atividade pode trazer consequências positivas e negativas, o objetivo deste trabalho é analisar, por meio de um estudo de casos, os impactos sociais, culturais, econômicos e ambientais do turismo em comunidades indígenas. Foi utilizado o método quantitativo com aplicação de questionários. As unidades de análise da pesquisa foram os indígenas moradores das comunidades pesquisadas. A amostra da pesquisa foi constituída de 210 respostas válidas. Para a análise dos dados utilizou-se estatística descritiva e análise multivariada. $O$ estudo revelou que a atividade turística pode trazer benefícios (econômicos, sociais, culturais e ambientais) para as comunidades, bem como sugere que sejam priorizadas ações que visem transformar as iniciativas existentes em destinos de excelência em turismo indígena.
\end{abstract}

Palavras-chave: Turismo Sustentável. Turismo Indígena. Indicadores de sustentabilidade. Desenvolvimento sustentável.

\begin{abstract}
This survey was conducted in three indigenous communities in the state of Roraima. They found in tourism a way of achieving local sustainable development. This activity can bring positive and negative consequences, so the aim of this study is to analyze the social, cultural, economic and environmental impacts of tourism in indigenous communities. We used the quantitative method with questionnaires. The units of analysis were the indigenous inhabitants of the surveyed communities. The survey sample consisted of 210 valid responses. In the data analysis, we used descriptive statistics and multivariate analysis. The study found that tourism can bring economic, social, cultural and environmental benefits for communities. Must develop actions that aim to transform existing initiatives in destinations of excellence in Indigenous tourism.
\end{abstract}

Keywords: Sustainable Tourism. Indigenous tourism. Sustainability indicators. Sustainable development.

1 Fundação Getulio Vargas - EAESP/FGV. Doutoranda em Administração de Empresas. E-mail: cristianne.brandao@gmail.com.

2 Fundação Getulio Vargas - EAESP/FGV. Doutor em Administração de Empresas, professor do PPG em Administração de Empresas. E-mail: jose.barbieri@fgv.br.

3 Universidade de Brasília - UNB. Doutor em Administração de Empresas. Email: edgarreyes2000@yahoo.com.br. 
Resumen: Esta encuesta se llevó a cabo en tres comunidades indígenas en el estado de Roraima. Que han hecho del turismo una alternativa para lograr un desarrollo local sostenible. Esta actividad puede traer consecuencias positivas y negativas, por lo que el objetivo de este estudio es analizar los impactos sociales, culturales, económicos y ambientales del turismo en las comunidades indígenas. Se utilizó el método cuantitativo con cuestionarios. Las unidades de análisis fueron los habitantes indígenas de las comunidades estudiadas. La muestra de la encuesta consistió de 210 respuestas válidas. Para el análisis de datos se utilizó estadística descriptiva y análisis multivariante. El estudio reveló que el turismo puede traer beneficios (económicos, sociales, culturales y ambientales) a las comunidades. Sugiere que se priorizan las acciones destinadas a la transformación de las iniciativas existentes en los destinos de excelencia en el turismo indígena.

Palavras-clave: Turismo Sostenible. El turismo indígena. Indicadores de sostenibilidad. Desarrollo sostenible.

\section{INTRODUÇÃO}

O turismo indígena ainda não é reconhecido como um segmento do turismo brasileiro, tampouco possui regulamentação. Porém, há diversas iniciativas de turismo em áreas indígenas espalhadas pelo país, mas não se sabe ao certo como a atividade está organizada e se realmente produz benefícios aos povos indígenas, pois são poucos os estudos empíricos sobre o tema, principalmente na região amazônica, onde se concentra a maior parte da população indígena no País.

Este trabalho apresenta uma pesquisa realizada em três comunidades indígenas: Bananal, Nova Esperança e Boca da Mata, pertencentes à Terra Indígena São Marcos, homologada em 1991 por meio do Decreto Presidencial 312/91, localizada no município de Pacaraima, estado de Roraima. Os povos indígenas, inicialmente, viviam principalmente do cultivo da mandioca, da caça e da pesca, entretanto, essa realidade tem se modificado, e cada vez mais se observa a constante busca por atividades que viabilizem a sustentabilidade econômica das comunidades. Há mais de uma década, as comunidades indígenas acima mencionadas tem vislumbrado no turismo uma alternativa para o desenvolvimento local sustentável. Esses grupos indígenas têm se mostrado empreendedores atuantes, que negociam parcerias com empresas privadas, elaboram projetos para obter financiamentos e tem assumido papel relevante na estrutura do setor. Partindo-se da premissa de que o turismo, dependendo do modo como for realizado, pode promover o desenvolvimento local sustentável para os povos indígenas, a pesquisa tem por objetivo analisar os impactos sociais, culturais, econômicos e ambientais do turismo em comunidades indígenas.

Este estudo se justificou pela preocupação com os impactos que o turismo pode gerar nas áreas indígenas, se não forem tomadas medidas que incluam as dimensões da sustentabilidade em seu desenvolvimento. Diversos estudiosos têm debatido os efeitos positivos e negativos do turismo sobre as culturas indígenas (SMITH, 2006; WEAVER, 2010). Além disso, observa-se que em Roraima, os indígenas elegeram o turismo como atividade capaz de proporcionar autonomia aos membros da comunidade, bem como a preservação de sua cultura e de seus valores tradicionais.

Após esta introdução, o trabalho aborda na seção seguinte os conceitos de turismo; turismo indígena, turismo sustentável, indicadores de turismo sustentável e desenvolvimento local sustentável. Na sequência apresenta a seção metodológica; os resultados da pesquisa e por fim, as considerações finais, onde são mencionadas as limitações do estudo e sugestões para pesquisas futuras. 


\section{DESENVOLVIMENTO LOCAL SUSTENTÁVEL}

A partir da década de 1970 foram publicados numerosos informes que mencionavam a preocupação em manter o crescimento econômico sem destruir o meio natural e social. A Comissão Mundial sobre Meio Ambiente e Desenvolvimento (CMMAD), criada pela Assembleia Geral da Organização das Nações Unidas (ONU) em 1983, em seu relatório denominado "Nosso Futuro Comum", lançado em 1987, enfatiza a necessidade de um novo modelo de desenvolvimento capaz de compatibilizar crescimento econômico, distribuição da riqueza e preservação ambiental. Dessa forma, define-se desenvolvimento sustentável como aquele que satisfaz as necessidades e as aspirações do presente, sem comprometer a capacidade das futuras gerações terem satisfeitas as suas necessidades (CMMAD, 1991). Os pontos centrais acerca do desenvolvimento sustentável, apresentados no relatório Nosso Futuro Comum (CMMAD, 1991), tornaram-se a base para a elaboração da agenda 21, que pode ser definida como um "instrumento de planejamento para a construção de sociedades sustentáveis, em diferentes bases geográficas, que concilia métodos de proteção ambiental, justiça social e eficiência econômica" (CNUMAD, 1992).

A segmentação por atividades ou por setores, conforme destacam Brandão et al (2010), é uma forma de operacionalizar as propostas desenvolvimento sustentável, assim, verifica-se sustentabilidade na construção civil, na arquitetura sustentável, finanças sustentáveis, turismo sustentável, entre outros setores econômicos. Ressalta-se que cada uma das dimensões ainda que sejam desagregadas para facilitar o entendimento acerca do desenvolvimento sustentável, não podem ser desenvolvidas isoladamente, pois estão inter-relacionadas.

$O$ desenvolvimento local, pode ser definido comum um processo endógeno de mudança (BUARQUE, 2002) que visa a melhoria da qualidade de vida e aumento da renda da população. Para ser consistente, mobiliza e utiliza de forma sustentável os recursos disponíveis de modo a contribuir com viabilidade e competitividade da economia local, bem como assegura a conservação do meio ambiente. Assim, o desenvolvimento local sustentável deve basear-se nos três pilares da sustentabilidade comentada acima, ou seja, proteção ambiental, justiça social e eficiência econômica. Sua prioridade é a melhoria na qualidade de vida das comunidades e o alcance de um modos vivendi mais sustentável (IPEA, 1996). Nessa perspectiva, o alcance do desenvolvimento local sustentável nas comunidades indígenas, pode resultar da integração do turismo, desde que o planejamento e gestão da atividade ocorram de modo participativo, e contemple o fortalecimento de um poder endógeno por parte das comunidades.

\subsection{Turismo e Turismo Indígena}

Segundo a Organização Mundial do Turismo (OMT), turismo é definido como o conjunto de atividades que as pessoas realizam durante viagens e estadas a lugares distintos de seu entorno habitual, por um período inferior a um ano, com fins de lazer, negócios e outros motivos não relacionados com o exercício de uma atividade remunerada no lugar visitado (OMT, 2001; UN, 2008). Murphy (2004) considera o turismo como uma das maiores indústrias do mundo. Segundo o autor, trata-se de um sistema complexo de partes integradas, que para cada dimensão recebe a atenção em diferentes momentos e locais, dependendo da finalidade específica. Bosh e Kambiz (2010) comentam que o turismo é um sistema dinâmico e complexo que envolve várias partes interessadas, com entendimentos, sistema de exploração e objetivos de gestão diferentes. Reid et 
al (2010) reforçam a ideia de que a indústria do turismo é uma das maiores e de mais rápido crescimento no mundo e uma das mais dinâmicas.

A indústria do turismo depende dos recursos naturais e culturais para atrair turistas. Nesse contexto, Murphy (2004) destaca a necessidade de regulamentação e de uma política para o setor. Para Lohmann e Netto (2008) a política pública compreende a direção dada pelo poder público federal, estadual e municipal ao desenvolvimento do turismo, sempre considerando os aspectos sociais, culturais, econômicos e ambientais.

Quanto ao turismo indígena, de acordo com Hinch e Butler (1996), o mesmo aparece como área de interesse científico a partir da década de 1970, com trabalhos de cunho antropológicos. Posteriormente, na década de 1990, o campo foi inserido no contexto de desenvolvimento econômico estratégico, que aperfeiçoou e analisou a relação contenciosa entre: comunidades indígenas, áreas protegidas e ecoturismo (SMITH, 2006). Durante essas duas fases questões relevantes começaram a ser moldadas de forma mais explícita dentro de um contexto de sustentabilidade. Hinch e Butler (1996); Smith (2006) comentam ainda acerca da evidente abordagem cada vez mais multi-disciplinar e interdisciplinar na evolução deste campo de estudos, decorrente da crescente participação de geógrafos, economistas, sociólogos, ecologistas políticos e outros cientistas sociais. Sinclair (2003) situa o subcampo mais claramente como um fenômeno interdisciplinar dentro dos estudos do turismo, considerando-o como um subconjunto do ecoturismo. Hinch e Butler (1996, p. 9) definem o turismo indígena como uma entidade mais como "atividade turística em que os povos indígenas estão diretamente envolvidos, quer através do controle ou por verem a sua cultura servir como a essência da atração".

\subsection{Turismo Sustentável}

O turismo é uma das muitas forças externas que influenciam a direção e as opções para o desenvolvimento local. Entretanto, é pertinente o questionamento da Comissão de Desenvolvimento Sustentável (CSD) em saber se "o turismo pode ser sustentável, isto é, se ele pode contribuir para desenvolvimento local sustentável, abordado no contexto da Agenda 21" (CSD, 1999). 0 Relatório Brundtland, mencionado anteriormente, formalizou o conceito de desenvolvimento sustentável como uma questão global, assim, essa expressão tem se expandido para abranger todas as formas de desenvolvimento e atividades econômicas, incluindo o turismo.

O turismo sustentável é um conceito e não uma modalidade de turismo, portanto, não deve ser confundido com ecoturismo, turismo cultural, turismo de aventura, turismo indígena, entre outros. No turismo, o conceito de sustentabilidade foi inicialmente estabelecido como uma noção de que existe a necessidade de equilibrar a inter-relação entre turismo e meio ambiente; que deve haver um compromisso em minimizar conflitos; e o planejamento deve ser exercido, de tal maneira, que a viabilidade da indústria em longo prazo seja salvaguardada (HUNTER E GREEN, 1995). Seja qual for o posicionamento, um tema comum entre essas perspectivas é que o desenvolvimento do turismo sustentável inclui o foco em alcançar algum nível de harmonia entre os grupos de partes interessadas para desenvolver uma qualidade de vida duradoura (SWARBROOKE, 2000; BYRD, 2007).

A OMT (2005) concebe o turismo sustentável como um processo que atende às necessidades atuais dos turistas e das comunidades receptoras, sem comprometer a capacidade de atender as necessidades das gerações futuras. Swarbrooke (2000, p.19) o define como "turismo que é economicamente viável, mas que não destrói os recursos dos quais o turismo do futuro dependerá, 
principalmente o meio físico e o tecido social da comunidade local". Nesse contexto, o desenvolvimento do turismo sustentável requer a participação de todos os interessados, cidadãos, empresários e líderes comunitários para garantir consenso nas decisões (WTO, 2004). O foco na participação das partes interessadas realça ainda mais a sua capacidade de lidar com vários problemas percebidos (WTO, 2004; BYRD, 2007; BUTTS E SINGH, 2010).

Alcançar o turismo sustentável requer monitoramento constante dos impactos, introduzindo medidas preventivas e/ou corretivas sempre que necessário, além disso, deve-se assegurar uma experiência significativa para os turistas, elevando sua consciência sobre as questões da sustentabilidade e promovendo práticas de turismo sustentável entre eles (OMT, 2004; JOHNSTON E TYRREL, 2007; JAYAWARDENA ET AL, 2008). Dessa maneira, para Nizic et al (2010) ter uma estrutura de gestão com metas claras e coerentes, determinadas em conjunto por todas as partes interessadas e com base na realidade das localidades e das regiões, além de usar da melhor maneira possível os recursos disponíveis, é um dos principais desafios do turismo sustentável. Assim, o turismo sustentável deve fazer uma utilização ótima dos recursos ambientais; respeitar a autenticidade sociocultural das comunidades anfitriãs, conservar o seu patrimônio cultural e valores tradicionais; além assegurar viabilidade e longo prazo das operações econômicas, proporcionando benefícios socioeconômicos a todos os interessados e que sejam distribuídos de forma justa, contribuindo para a redução da pobreza (WTO, 2001). Para que isso aconteça, é necessária a utilização de indicadores precisos e confiáveis, capazes que de atestar a sustentabilidade do turismo.

\subsection{Indicadores de Turismo Sustentável}

Indicadores, segundo a OMT (2004) são conjuntos de informações formalmente selecionadas para serem usadas em uma base regular de forma a medir importantes mudanças no desenvolvimento e gestão do turismo. São medidas que ajudar descobrir a existência e gravidade de problemas atuais, sinais de problemas futuros, meios para identificar e medir os resultados de ações antrópicas e, dessa forma, facilitar o processo de tomada de decisão (UN, 2001). Nesse contexto, Ciegis (2009) complementa que os indicadores são desenvolvidos como uma ferramenta simplificada, que facilita a comunicação, servindo de base para as decisões políticas em busca de sustentabilidade.

Para o IBGE os indicadores reportam-se a fenômenos de curto, médio e longo prazo. Tornam viável o "acesso integrado à informação já disponível sobre temas relevantes para o desenvolvimento, assim como apontam a necessidade de geração de novas informações" (IBGE, 2008). Servem ainda para identificar variações, comportamentos, processos e tendências. Nessa perspectiva, a OMT criou um conjunto de indicadores básicos, elaborados para uso em diversos destinos turístico. Depois, foram sendo criados indicadores complementares concebidos para tipos específicos de destinos, como: resorts costeiros, cultural, ecoturismo, dentre outros, de maneira que acabaram por complementar as informações do conjunto anterior.

Desse modo, segundo Brasil (2004), o destino turístico deve ser avaliado constantemente, assim como, seus avanços e retrocessos devem ser monitorados e medidos por meio de indicadores, tendo em vista que não existe sustentabilidade permanente, em função dos seus fatores condicionantes serem muitos e se modificarem ao longo do tempo. Assim, se é possível afirmar que o turismo contribui para a sustentabilidade das comunidades indígenas, essa contribuição deve ser passível de medição. Para a OMT (2004), em qualquer destino, os melhores indicadores são aque- 
les que respondem aos principais riscos e preocupações em relação à sustentabilidade do turismo, bem como, fornecem informações que podem ajudar a esclarecer questões e dar respostas.

Os indicadores normalmente respondem a questões relativas aos recursos naturais de um destino, as preocupações relativas à sustentabilidade econômica, às questões relativas aos bens culturais e valores sociais, e mais amplamente à questões de organização e gestão do destino (WTO, 2004). Nesse contexto, o desenvolvimento e a utilização de indicadores são cada vez mais vistos, como uma parte fundamental do planejamento e gestão dos destinos e um elemento integrante dos esforços para promover o desenvolvimento sustentável do turismo em todas as escalas.

\section{METODOLOGIA}

A pesquisa teve como objetivos analisar os impactos sociais, culturais, econômicos e ambientais do turismo nas comunidades indígenas na perspectiva dos residentes. $O$ estudo se caracteriza como exploratório-descritivo, pois descreve e analisa de que maneira o fenômeno ocorre, bem como suas características e natureza. Já a estratégia de pesquisa adotada foi o estudo de caso, que segundo Yin (2010) contribui com o conhecimento de fenômenos individuais, organizacionais, políticos, sociais, grupais e relacionados, suscitados pelo desejo de compreender fenômenos sociais complexos.

Considerando a existência de diversas iniciativas no Estado de Roraima relacionadas com o turismo indígena, ainda que incipiente comparativamente ao que ocorre em outros países, conforme literatura revisada, essas iniciativas foram examinadas, e são as unidades de análise dessa pesquisa. Para Yin (2010) as unidades de análise estão entre os componentes mais importantes para o estudo de caso, conforme o autor citado. Desse modo, foram analisadas três iniciativas de turismo em área indígena no estado de Roraima, a saber: Comunidade Indígena Nova Esperança, Comunidade Indígena de Bananal e Comunidade Indígena da Boca da Mata.

Adotou-se o método quantitativo e a pesquisa foi realizada por meio da aplicação de questionário. $\mathrm{O}$ instrumento de coleta utilizado nesta pesquisa foi adaptado do Workshop on Indicators for the Sustainable Development of Tourism, OMT (2000), cujo objetivo consistiu no desenvolvimento e teste de indicadores de turismo sustentável para o destino turístico de Beruwala, no Sri Lanka. O principal motivo que levou à escolha deste questionário, é que o mesmo foi elaborado para a análise dos impactos do turismo em pequenas comunidades, podendo assim atender o propósito desse estudo.

O instrumento foi constituído de duas seções: uma referente às características sócio demográficas dos entrevistados, como idade, gênero, situação de emprego e ganhos com o turismo. A segunda consistiu na verificação dos impactos ambientais, culturais, sociais e econômicos provenientes do turismo nas comunidades indígenas. Como o questionário original foi elaborado em inglês foi necessária tradução. Realizou-se, portanto, a tradução reversa da seguinte maneira: um professor de inglês brasileiro fez a tradução para o português. Depois um cidadão de origem britânica, que tem o inglês como primeira língua, mas com fluência em português, fez a tradução para o inglês. Dessa forma foi possível comparar o texto com o resultado e verificar se houve alguma distorção na tradução. Após a tradução realizou-se o pré-teste do questionário com dez indígenas. Durante o pré-teste, somente dois respondentes apresentaram dificuldades no entendimento de algumas questões. Dessa forma, o pesquisador teve que explicar de maneira mais simples para 
que o entrevistado compreendesse e escolhesse a opção mais adequada, com base em seu entendimento.

Na sequência, foi definida população alvo, que segundo Hair (2005, p. 239) "é o grupo completo de objetos ou elementos relevantes para a pesquisa, e são importantes por possuírem as informações que o projeto de pesquisa se propõe a coletar". Assim, a população alvo desta pesquisa foram os indígenas com idade igual ou superior a 15 anos, residentes das comunidades indígenas Bananal, Boca da Mata e Nova Esperança, que formaram as unidades de análise desta pesquisa. A coleta dos dados foi realizada entre os meses de março a junho de 2012. Os dados foram coletados in loco nas três comunidades mencionadas. Para a coleta de dados, a equipe permaneceu por sete dias em cada comunidade. Durante a aplicação dos questionários, tomaramse os devidos cuidados para garantir que os respondentes tivessem o entendimento acerca de todas as questões. De modo que, a escolha das respostas ocorresse de maneira consciente e segura.

A amostra da pesquisa foi constituída de 210 respostas válidas. O questionário foi composto de 40 afirmações que proporcionou uma razão de 5 casos por afirmação, utilizando uma escala intervalar de 5 pontos (5 - concordo totalmente até 1 - discordo totalmente). Hair (2005) alega como aceitável um mínimo de 5 casos por variável, porém para uma confiabilidade maior de análise seria necessário manter uma proporção acima de 10 casos por variável. Em função disso, optou-se pela análise fatorial intrabloco, para verificar se as variáveis formam uma dimensão, ou seja, avaliar a unidimensionalidade do construto, como mencionam Mondadori e Ladeira (2007). Utilizou-se o procedimento Categorical Principal Components Analysis - CAPCA indicado por Meulman e Heiser (2005), que é um método que visa resumir um grupo de dados, de maneira similar ao modelo de análise convencional. É uma opção alternativa quando as suposições de linearidade entre as variáveis, escalas intervalares e distribuição normal não são atendidas. Com base no resultado do teste de normalidade, verificou-se que as suposições de homocedasticidade e normalidade não foram atendidas. Depois de verificados os pressupostos, definiu-se o método com foco nas provas não paramétricas. Tais análises, de acordo com Levine et al (2000) e Pontes (2005), requerem procedimentos menos rígidos, além de manter suas propriedades independentemente da forma de distribuição dos dados.

Decidiu-se fazer a comparação entre dois grupos, neste caso, recomenda-se realizar o teste t. Contudo, quando o pressuposto como a normalidade não são confirmados, deve-se realizar a estatística Mann-Whitney, que é o teste não paramétrico equivalente (LEVINE et al, 2000). A estatística mostra os valores de mean-rank, que são utilizadas para identificar qual dos grupos apresentou opinião positiva a respeito da sustentabilidade no turismo nos aspectos social, cultural, ambiental e econômico. Neste caso, o valor de $p$ (Asymp. Sig.) é um critério para definir se existe ou não diferenças significativas entre os grupos.

Para análise dos dados foi utilizada estatística descritiva (frequências) para caracterizar a amostra (etapa sócio demográfica do questionário); análise fatorial para verificar se a dimensão proposta é unidimensional (a técnica específica para realização do resumo foi a CATPCA) e; alpha de Cronbach utilizado para verificar a consistência da dimensão. Por último foram realizadas provas não paramétricas de Mann-Whitney, para a comparação entre grupos. As análises foram viabilizadas por meio do software SPSS versão 18.0. 


\subsection{Descrição das Comunidades Indígenas}

A comunidade indígena Bananal foi criada em 1969 com o nome de Macayapan (Bananal, na língua indígena Wapixana), fundada por Bento Louredo da Silva e sua esposa Rosa Contrera, ambos venezuelanos que migraram para Brasil (Roraima), com seus oito filhos. Mais tarde, em 1972 a comunidade popularizou-se com o nome de Bananal, devido à plantação de banana nativa existente. Atualmente vivem cerca de 200 habitantes. Viviam principalmente da agricultura, que até hoje é a principal fonte de renda.

A comunidade conta com uma escola estadual, que atende desde a educação infantil, até o ensino médio. A energia elétrica é fornecida por meio de um gerador, fornecido e abastecido pela Central Elétrica de Roraima (CER), concessionária de energia do estado de Roraima, que atende cerca de $80 \%$ da população. Quanto ao abastecimento de água, é captada de fonte natural. A comunidade construiu uma barragem de onde a água é captada por gravidade. A água é encanada e abastece toda a população.

A comunidade promove duas grandes festas que reúne outras comunidades, são elas, a Festa da Damorida, no dia do índio e a Feira de Artesanato, que ocorre no mês de julho. A comunidade é formada pelas etnias, Taurepang (maioria), Macuxi e Wapixana. Maior parte da população trabalha na agricultura e pecuária. A atividade de turismo na comunidade do Bananal teve início há mais de dez anos, seguindo o exemplo de seus "parentes" da Venezuela, que há muito tempo vivem do turismo. Assim, a comunidade participou de diversos cursos de capacitação, como: Atendimento ao turista, condutor de visitantes, boas práticas na manipulação de alimentos, dentre outros, realizados pelo SEBRAE, IFERR e Departamento de Turismo. A divulgação dos atrativos da comunidade é feito por meio de mídias sociais. Geralmente os visitantes são pesquisadores e estudantes de turismo do IFERR, de universidade do Estado do Amazonas e do Instituto de Pesquisa da Amazônia - INPA. Os principais atrativos são a cultura indígena, cachoeiras, serras, fauna e flora.

A Comunidade Nova Esperança se instalou, em 1996, numa área onde viviam cerca de dez agricultores que fizeram grandes desmatamentos para trabalhar a pecuária extensiva. Com a saída dos mesmos, a comunidade herdou uma quantidade de área sem mata nativa, os leitos de igarapés com alto grau de ações antrópicas e poucas caças. As famílias que residem na Comunidade Nova Esperança são formadas por três etnias: Taurepang, Wapixana e Macuxi. São os povos com maior tempo de contato com a sociedade envolvente. Seus principais traços culturais sofreram profundas mudanças, na língua, na construção de suas habitações, hábitos alimentares, etc. Em 2000 as lideranças indígenas se reuniram para elaborar um planejamento de curto, médio e longo prazo para a comunidade. Assim, foi criada a ONG PRONESP - Programa de Desenvolvimento Sustentável de Nova Esperança. Ao realizar, por meio da ONG, um diagnóstico da comunidade, verificou-se vários aspectos positivos como a boa localização, o fato de a comunidade não apesentar vícios de paternalismo, potencial para o ecoturismo, lagos perenes que poderiam ser adaptados para a criação de peixes, dentre outros.

A comunidade decidiu investir no turismo, e no primeiro trimestre de 2001 participou de uma oficina de sensibilização realizada por consultor do PROECOTUR - Programa de Desenvolvimento do Ecoturismo na Amazônia Legal, do Ministério do Meio Ambiente. Posteriormente, participou do 70 edital do PPP- Programa de Pequenos Projetos. O programa é financiado pelo Small Grants Programme (SGP), vinculado ao Fundo para o Meio Ambiente Global (GEF) da Organização das Nações Unidas. O PRONESP teve aprovado um projeto para realizar a capacitação dos 
moradores da comunidade, de forma que os mesmos tivessem preparados para receber os turistas. Daí por diante a comunidade, ao longo dos últimos onze anos vem trabalhando no turismo. Atualmente, os moradores trabalham para melhorar a infraestrutura na comunidade, com construção de pousada, restaurante e expansão das lojas de artesanatos. Os principais atrativos turísticos da comunidade são: as inúmeras trilhas ecológicas existentes, sendo a principal delas denominada Trilha do Coatá. Cuja caminhada é feita em meio à mata nas proximidades da aldeia. Um percurso de $7 \mathrm{~km}$ onde é possível encontrar sítio arqueológico, espécies nativas de flora, plantas medicinais e presenciar o canto de várias espécies de aves, além dos macacos Coatá, que dão nome à trilha e são abundantes na localidade. A comunidade pretende, em breve, instalar um pesque e pague indígena, no qual serão utilizados, ao invés de linha e anzól, canoa, arco e flecha.

Na comunidade indígena Boca da Mata, vivem 513 pessoas e pouco mais de $25 \%$ são funcionários públicos. Na aldeia convivem Taurepang, Makuxi e Wapichana. Os tuxauas se alternam entre as três etnias. O desenvolvimento do turismo na comunidade, data do final da década de 1990, época em que teve início o Programa de Municipalização do Turismo - PNMT, do Ministério do Turismo. Na ocasião, quinze pessoas participaram das oficinas do programa. Posteriormente, a comunidade recebeu outros cursos de capacitação para o turismo, promovidos pelo Departamento de Turismo de Roraima, SEBRAE/RR e Ministério do Meio Ambiente. Atualmente 50 pessoas estão participando do curso de Técnico em Turismo, que é ministrado na própria comunidade, pelo SENAC. Os indígenas acreditam que o turismo é uma oportunidade de negócio que favorece o desenvolvimento local nas comunidades. Os principais atrativos da comunidade são: cachoeiras; corredeira do rio Surumu, propícias à prática de rafting e canoagem; pesca e trilhas na mata.

As três comunidades pesquisadas atuam no turismo há pelo menos dez anos. Duas delas participaram das oficinas do Programa de Municipalização do Turismo - PMNT, do Governo Federal ainda na década de 1990. A partir de então, passaram a atuar no turismo sem qualquer apoio do poder público, sendo essa, inclusive, uma das principais dificuldades em desenvolver a atividade.

O modo como o turismo é operacionalizado é similar nas três comunidades. O turista chega até a comunidade e é recepcionado pelos guia/condutores locais. Em alguns casos, são conduzidos para assistir uma apresentação de dança realizada pelos jovens ou pelos anciãos da comunidade. Depois, recebem instruções sobre o que é permitido ou não na comunidade; sobre os cuidados quanto aos animais peçonhentos; sobre o trajeto das trilhas; horário das refeições, dentre outras informações. A partir de então, o turista (individual ou grupo) são conduzidos aos atrativos, onde podem observar e fotografar a fauna e a flora, bem como, apreciar os banhos nas diversas cachoeiras. Quando retornam das trilhas, geralmente no horário do almoço, a mesa está posta com diversos pratos da culinária indígena, que inclui a Damorida (caldeirada de peixe regado a diversos tipos de pimenta); o beiju (feito da mandioca); o caxiri (bebida feita da batata doce ou do cajú); o pajuarú (bebida típica feita da mandioca), dentre outras opções.

Depois da refeição os turistas são levados para conhecer o artesanato indígena, que é comercializado na comunidade. Algumas vezes são oferecidas oficinas de confecção de artesanato, na qual o turista participa desde a coleta da matéria prima até as técnicas de trançado. Ao final do dia, o turista deixa a comunidade. Alternativamente, quando o turista pernoita na comunidade, geralmente à noite, são feitas rodas em torno de uma fogueira e os anciãos contam as lendas e ensinam a língua materna. 


\section{RESULTADOS}

A primeira parte refere-se aos dados sociodemográficos e a segunda etapa é referente à análise dos impactos do turismo nas dimensões social, cultural, ambiental e econômica na visão dos residentes. Verificou-se que não há diferença considerável nos gênero dos respondentes. São do sexo feminino $48 \%$ dos respondentes, e os do sexo masculino totalizaram pouco mais de $51 \%$. Quanto à faixa etária, observou-se que as comunidades indígenas onde a pesquisa foi aplicada, são compostas por uma população jovem, na faixa de 15 a 25 anos, com 32,38\%, conforme Figura 1. Pessoas com faixa etária entre 25 a 34 e 35 a 44, totalizaram pouco mais de $20 \%$ cada. E pessoas entre as faixas etárias 45 a 54; 55 a 64 e; 75 ou mais, totalizaram menos de $10 \%$ cada.

Figura 1 - Gênero

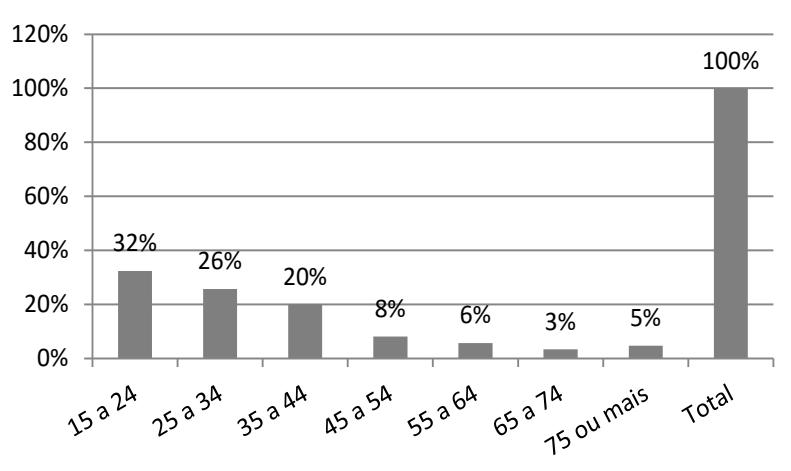

Sobre a situação de emprego dos respondentes, observou-se que $29 \%$ dos respondentes declararam que não estão empregados no momento; $4 \%$ informaram que são estudantes sem emprego ou subsídios, entretanto, alguns respondentes declararam que trabalham ocasionalmente no turismo. $13 \%$ dos respondentes são empregados em tempo parcial. Tanto os empregados em tempo integral, quanto os aposentados totalizaram $10 \%$ cada um. Enquanto que, os casualmente ou sazonalmente empregados totalizaram $8 \%$. E por fim, os que responderam que recebe pensão ou subsídios totalizou 1\%, conforme Figura 2.

Figura 2 - Situação de Emprego*

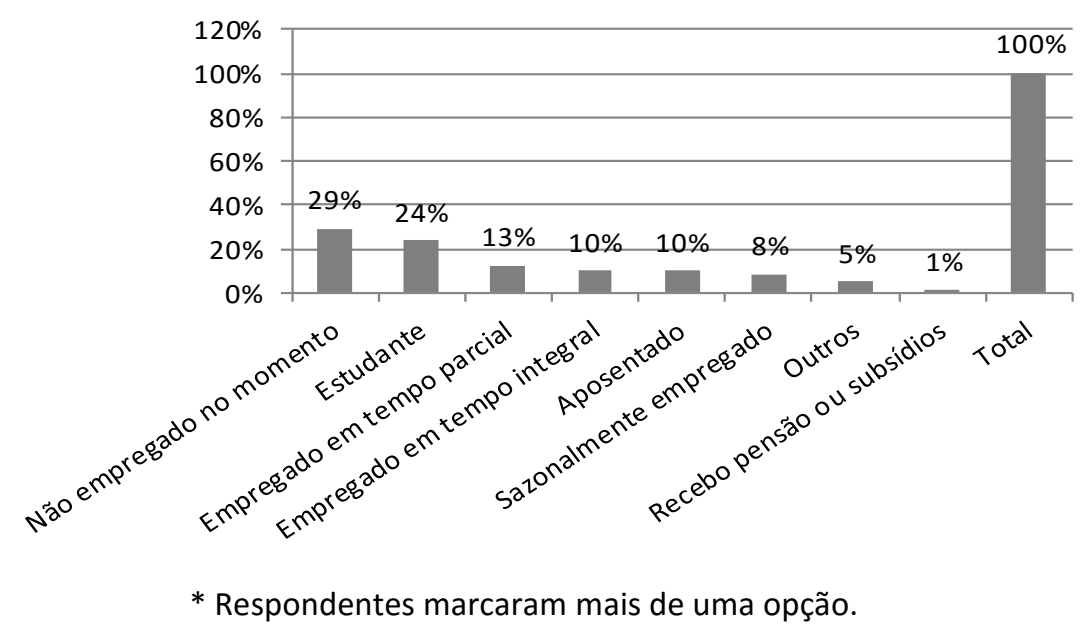


A renda das comunidades vem predominantemente da agricultura conforme $40 \%$ dos respondentes. Nota-se que a segunda atividade é o turismo, com 33\% das respostas, entretanto, ressalta-se que os respondentes não selecionaram a opção turismo como única atividade, ela sempre está acompanhada de alguma outra atividade. Na maioria dos casos, o turismo é a segunda fonte de renda dos respondentes. Seguido outras áreas, que totalizou 14\%. Outros $9 \%$ responderam que atuam na educação. Por fim, atividades como comércio e pesca totalizaram $2 \%$ cada, conforme se verifica na Figura 3.

Figura 3 - Área de atuação*

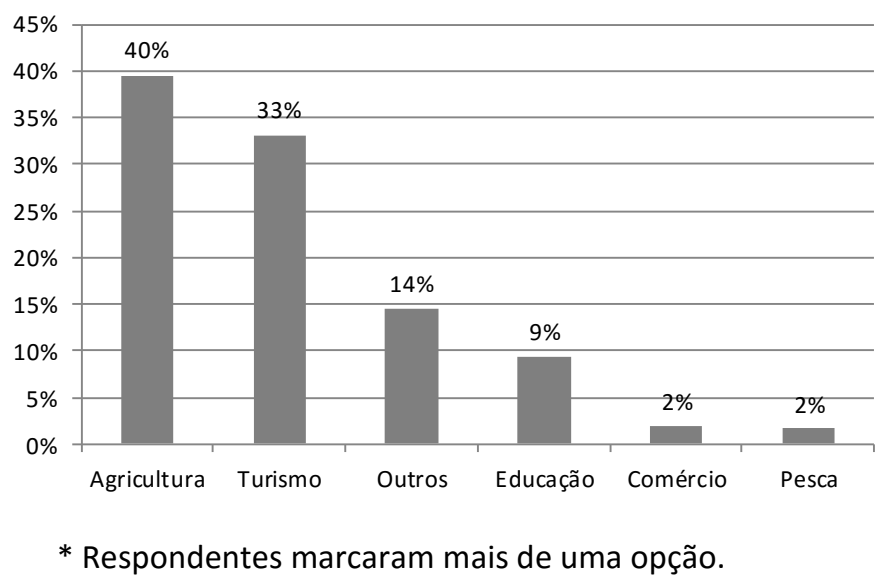

Vários respondentes comentaram que o turismo é uma atividade que pode fazer com que os jovens permaneçam nas aldeias. Pois existe uma tendência de os jovens deixarem a comunidade e migrarem para a cidade, em busca de emprego e melhores condições de vida. Maioria deles tem o segundo grau completo e muitos estão cursando nível superior e não querem mais trabaIhar na agricultura, ficando essa atividade destinada aos mais velhos. Cerca de 50 pessoas da comunidade Boca da Mata, por exemplo, estão matriculados em um curso técnico de turismo e hospitalidade, ministrado pelo SENAC/RR. É um indicador de que as pessoas estão investindo na atividade e pretendem atuar na área.

A Figura 4 apresenta as áreas de atuação no turismo. Assim, 2\% dos respondentes afirmaram trabalhar nos atrativos. Estes, geralmente, moram próximo a cachoeira ou trilhas e cuidam da manutenção daquela área. Na parte de acomodação/hospedagem, trabalham 3\% dos respondentes; enquanto que ao artesanato indígena dedicam-se $8 \%$ dos moradores. Com relação ao guiamento, são $15 \%$ atuando nessa área; já na alimentação, atuam $20 \%$ dos respondentes. A opção "outros" que obteve $52 \%$ das respostas é composta por participantes de grupos de dança, apresentações culturais e contadores de histórias, que se revezam nessas atividades. 
Figura 4 - Área de atuação*

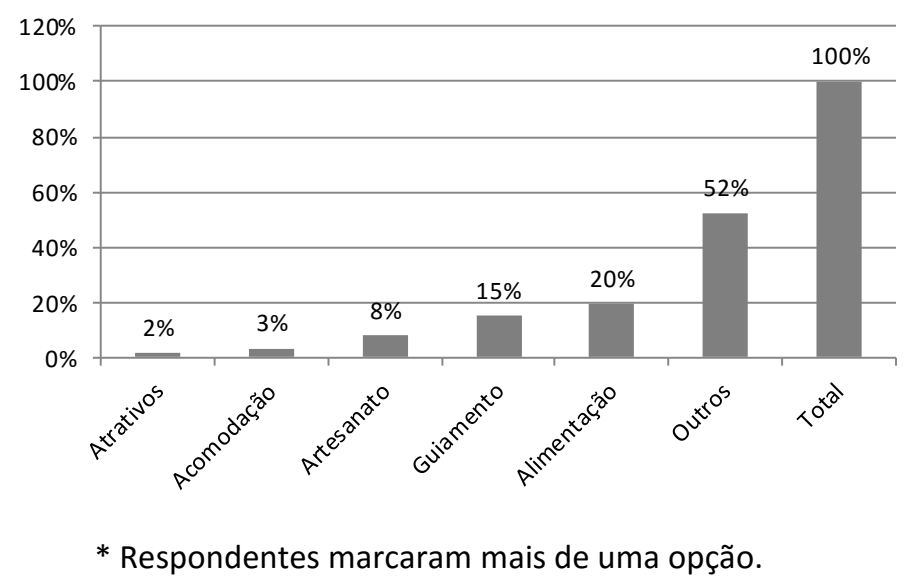

No que se refere ao percentual da renda proveniente do turismo, verificou-se que a maioria dos entrevistados (139 pessoas) não sabe informar quanto da sua renda vem do turismo ou não possui renda no turismo, como se observa na Figura 5. Pode parecer contraditório este resultado, se comparado com o que foi apresentado na Figura 3, onde o turismo aparece como a segunda atividade mais praticada. Contudo, ressalta-se que menos da metade dos residentes das três comunidades, conseguem calcular quanto de sua renda é proveniente do turismo. A maioria, talvez pelo ritmo esporádico da atividade, não consegue precisar o percentual ganho com turismo. Como se vê, 39 respondentes afirmaram que $5 \%$ de sua renda é proveniente das atividades do turismo. Outras 25 pessoas disseram que $10 \%$ do total de sua renda origina-se do turismo. Quatro respondentes informaram que a renda proveniente do turismo é de $20 \%$. Por fim, três respondentes afirmaram que o turismo corresponde a $30 \%, 50 \%$ e $80 \%$ da renda de cada um.

Figura 5 - Percentual de renda proveniente do turismo

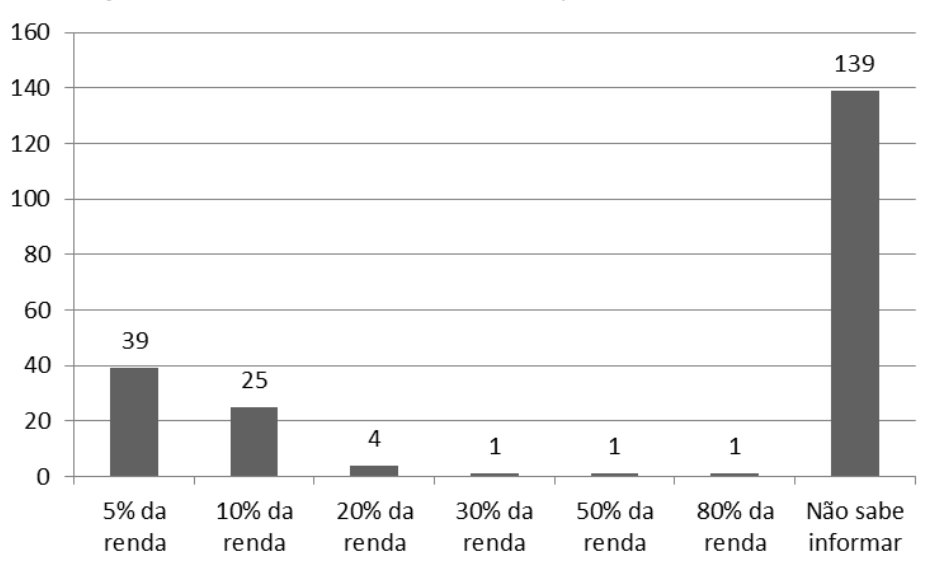

\subsection{Análise dos impactos do turismo nas dimensões social, cultural, ambiental e econômica.}

Nesta fase, a Análise Fatorial Exploratória - AFE foi utilizada para analisar a unidimensionalidade das 40 afirmativas sobre sustentabilidade do turismo dispostas em cada uma das 4 dimensões estudadas na pesquisa, quais sejam: social, cultural, ambiental e econômica. Assim, foi realizada AFE intrabloco para cada uma das dimensões. Adiante são apresentadas as medidas resumo 
das análises, são elas: a dimensão estudada, o alfa de Cronbach e a percentagem de variância explicada. Esperava-se que cada uma das dimensões apresentasse alfa de Cronbach acima de 0,6, autovalor acima de 1 e \% de variância acima de 0,5, conforme Hair (2005).

Num primeiro momento, realizou-se a análise para verificar se as afirmações referentes à dimensão social formariam uma única dimensão. Neste caso, uma análise obtendo 1 dimensão das 10 variáveis do constructo foi obtida. Por meio da análise, percebeu-se que a primeira dimensão apresentou autovalor acima de 1, seguido de um Alfa de Cronbach de 0,797. Porém, o valor da variância explicada ficou em 0,35 , um número abaixo do esperado, como mostra a Tabela 1 . Por meio da análise, percebeu-se que a primeira dimensão apresentou autovalor acima de 1 seguido de um Alfa de Cronbach de 0,695, além de um valor de \% de variância explicada em 0,52, número contido na faixa requerida. A Tabela 2 apresenta o resumo do processo.

Os mesmos procedimentos apresentados nas Tabelas 1 e 2 foram realizados com as demais dimensões.

Tabela 1 - Verificação unidimensionalidade Social

\begin{tabular}{c|r|r|r}
\hline \multirow{2}{*}{ Dimension } & \multirow{2}{*}{ Cronbach's Alfa } & \multicolumn{2}{|c}{ Variância Explicada } \\
\cline { 3 - 4 } & & Auto Valores & \% de Variância explicada \\
\hline \multirow{2}{*}{ Total } &, 797 & 3,535 & 35,346 \\
&, 797 & 3,535 & 35,346 \\
\hline
\end{tabular}

Tabela 2 - Análise unidimensionalidade dimensão social

\begin{tabular}{ccccc}
\hline ACP & Alfa & Autovalor & $\begin{array}{c}\text { \% variância } \\
\text { explicada }\end{array}$ & $\begin{array}{c}\text { Variável a ser retira- } \\
\text { da }\end{array}$ \\
\hline 1 &, 797 & 3,535 & 35,346 & 10 \\
2 &, 793 & 3,385 & 37,612 & 4 \\
3 &, 785 & 3,196 & 39,950 & 7 \\
4 &, 775 & 2,982 & 42,604 & 3 \\
5 &, 759 & 2,720 & 45,337 & 1 \\
6 &, 737 & 2,436 & 48,712 & 2 \\
7 &, 585 & 1,781 & 44,533 & 6 \\
8 &, 695 & 2,089 & 52,224 & - \\
\hline
\end{tabular}

Na Tabela 3 são apresentados os resumos das AFEs realizadas. Pode-se observar que todas as dimensões apresentaram Alfa de Cronbach acima 0,6; autovalor acima de 1 e \% de variância acima de 0,5 .

Tabela 3 - Resumo Análise Fatorial Intrabloco

\begin{tabular}{l|r|r|r}
\hline \multirow{2}{*}{ Dimensão } & \multirow{2}{*}{ Alfa de Cronbach } & \multicolumn{2}{|c}{ Variância Explicada } \\
\cline { 3 - 4 } & & Auto Valor & \% de Variância Explicada \\
\hline Social &, 695 & 2,089 & 52,22 \\
Cultural &, 662 & 1,709 & 56,96 \\
Ambiental &, 869 & 2,874 & 71,85 \\
Econômica &, 725 & 2,193 & 54,84 \\
\hline
\end{tabular}


A Tabela 4 apresenta os pesos das dimensões estudadas. Pode-se verificar que os resultados foram significativos para formar a dimensão social, utilizando 4 das 10 afirmações propostas no questionário. Para formar a dimensão cultural, utilizou-se 3 das 10 afirmações.

Tabela 4 - Pesos das dimensões

\begin{tabular}{|c|c|c|}
\hline \multirow{2}{*}{ Dimensão } & \multirow{2}{*}{ Carga dos Fatores } & Dimension \\
\hline & & 1 \\
\hline \multirow{4}{*}{ Social } & DIM_SOC2 & ,718 \\
\hline & DIM_SOC5 & ,728 \\
\hline & DIM_SOC8 & 735 \\
\hline & DIM_SOC9 & ,709 \\
\hline \multirow{3}{*}{ Cultural } & INV_DIM_CUL7 & ,780 \\
\hline & INV_DIM_CUL9 & 749 \\
\hline & INV_DIM_CUL10 & ,734 \\
\hline \multirow{4}{*}{ Ambiental } & INV_DIM_AMB2 & ,770 \\
\hline & INV_DIM_AMB3 & ,893 \\
\hline & INV_DIM_AMB4 & 871 \\
\hline & INV_DIM_AMB8 & ,851 \\
\hline \multirow{3}{*}{ Econômica } & DIM_ECO3 & 737 \\
\hline & DIM_ECO4 & ,899 \\
\hline & DIM_ECO5 & ,785 \\
\hline
\end{tabular}

\subsection{Comparação de Grupos}

Mediante ao fato de que os scores das dimensões não apresentaram distribuição normal (Teste de Kolmorogov-Smirnov), foi utilizada a prova não paramétrica de Mann-Whitney para testar as diferenças entre dois grupos.

Foram analisadas as diferenças entre as opiniões dos respondentes dividindo-os em dois grupos por atividade econômica. Foram analisadas as diferenças entre as atividades de agricultura e depois as atividades de turismo. Diante disto, pode-se demonstrar como os respondentes opinaram a respeito de quais dimensões possuem importância significativa na sustentabilidade no turismo.

Após as análises, observou-se que os respondentes atuantes na área de agricultura demonstraram maior grau de positividade em relação a sustentabilidade no turismo na dimensão cultural, como mostra a Tabela 5, com o valor de mean-rank de 107,46.

Tabela 5 - Análise das dimensões por atividade (agricultura)

\begin{tabular}{lccc}
\hline \multicolumn{1}{c}{ Agricultura } & Não & Sim & Asymp. Sig. (p) \\
\hline D. Social (mean-rank) & 116,310 & 97,850 & 0,026 \\
D. Cultural (mean-rank) & 102,720 & 107,460 & 0,547 \\
D. Ambiental (mean-rank) & 113,630 & 99,750 & 0,050 \\
D. Econômica (mean-rank) & 110,490 & 101,970 & 0,250 \\
\hline
\end{tabular}


Contudo, ao observar o valor de $p$, percebe-se que essa diferença não é significativa entre os respondentes. Observa-se que existiram diferenças significativas nas dimensões social e ambiental, com os valores de 0,026 e 0,05 respectivamente.

Os respondentes atuantes na área de turismo também demonstraram maior grau de positividade em relação a sustentabilidade no turismo na dimensão cultural, como é visto na Tabela 6 com o valor de mean-rank de 120,96.

Tabela 6 - Análise das dimensões por atividade (turismo)

\begin{tabular}{lccc}
\hline \multicolumn{1}{c}{ Turismo } & Não & Sim & Asymp. Sig. (p) \\
\hline D. Social (mean-rank) & 122,670 & 87,660 & 0,000 \\
D. Cultural (mean-rank) & 90,620 & 120,960 & 0,000 \\
D. Ambiental (mean-rank) & 108,250 & 102,640 & 0,421 \\
D. Econômica (mean-rank) & 105,300 & 105,700 & 0,956 \\
\hline
\end{tabular}

Ao observar o valor de Asymp. Sig., percebe-se que existe diferença significativa entre os respondentes, ou seja, para as pessoas que trabalham na área de turismo, o impacto no sustentabilidade do turismo é maior na dimensão cultural. Observa-se que existiram diferenças significativas na dimensão social com valor de 0,000 . Porém, os menores valores de "mean rank" foram relacionados com a área de turismo, isto é, 87,66, o que demonstra que as demais áreas possuem maior positividade em relação à sustentabilidade na dimensão social.

Para realizar os testes de comparação de grupos foram utilizadas as dimensões social, cultural, ambiental e econômica. Os scores foram estimados conforme as categorias encontradas nas análises fatoriais, o que gerou as variáveis das dimensões citadas.

Antes de continuar a discussão, é pertinente relembrar a definição de turismo indígena. Que segundo Hinch e Butler (1996) é a atividade turística em que os povos indígenas estão diretamente envolvidos e têm controle sobre a atividade. Assim, o turismo que acontece nessas comunidades pode ser considerado turismo indígena, tendo em vista que eles próprios organizam e gerenciam a atividade, sem qualquer participação do Governo, ONGs ou qualquer outra instituição.

Com base no exposto, o que se pretendia com esta pesquisa, era verificar a opinião dos residentes quanto à sustentabilidade do turismo, verificando os impactos positivos advindos dessa atividade nas dimensões social, cultural, ambiental e econômica. Assim, diante dos resultados da comparação por grupos, percebeu-se que o turismo tem impactado positivamente nas comunidades indígenas quanto às dimensões social, ambiental e cultural, segundo a opinião dos residentes. Resultados apontaram que os impactos advindos do turismo, segundo a opinião dos residentes, foram positivos até o momento. Pelo menos nas dimensões social, cultural e ambiental. Contudo, com relação à sustentabilidade econômica, não apresentou resultado representativo. Uma das razões para este resultado pode dever-se ao fato de as comunidades operarem com número reduzido de visitantes. Talvez esse resultado fosse diferente se houvesse um fluxo maior e mais constante de turistas nessas localidades. A OMT (2002) reforça que os princípios de sustentabilidade, referem-se ao um equilíbrio adequado quanto aos aspectos ambientais, econômicos e socioculturais do turismo, de modo a garantir a sua sustentabilidade em longo prazo. O que, conforme resultado analisado, ainda não ocorre em todas as dimensões nas comunidades pesquisadas. 
O resultado da pesquisa é consistente com as afirmações de autores como Swarbrooke (2002) que diz que o turismo sustentável, além de ser capaz de contribuir para o desenvolvimento, pode trazer efeitos imediatos tanto para as comunidades receptoras quanto para os visitantes. Entretanto, considera-se necessário o permanente monitoramento da atividade nas terras indígenas. Tendo em vista que, segundo Butler (1999) mesmo que a atividade seja focada no turismo sustentável em qualquer uma de suas dimensões e seja desenvolvido por residentes locais, sem a utilização de indicadores precisos, confiáveis e monitoramento, não se pode confirmar a permanência da sustentabilidade em qualquer destino turístico.

\section{CONSIDERAÇÕES FINAIS}

Este estudo teve como objetivo analisar os impactos do turismo nas dimensões social, cultural, econômica e ambiental nas comunidades indígenas na perspectiva dos moradores das comunidades indígenas.

No que se refere ao aspecto econômico, pôde-se constatar, de maneira geral, um incremento na renda das comunidades indígenas. Como mencionado por vários residentes, este aumento na renda é percebido mais individualmente do que coletivamente. Verificou-se que a maioria não sabe informar ou não tem renda proveniente do turismo. Assim, não se pode precisar os ganhos anuais advindos da atividade. Tal fato dificulta o planejamento de ações futuras, bem como, investimentos em infraestrutura. No aspecto sociocultural, os povos indígenas perceberam melhorias na autoestima, na valorização da cultura e um aumento no interesse dos mais jovens em aprender a língua materna. As festas típicas e o artesanato também passaram a ser mais procurados. Já no aspecto ambiental verificou-se o interesse na conservação do meio ambiente, na redução das queimadas, manutenção das trilhas e limpeza nos arredores da comunidade. De modo geral, as três comunidades possuem rios e matas preservadas e com abundância de animais silvestres, possíveis de se observar com facilidade. Constataram-se também problemas de saneamento básico e gerenciamento dos resíduos sólidos nas comunidades pesquisadas. Como forma atenuar os problemas dos resíduos sólidos, uma das comunidades recomenda que os turistas levem de volta todo o lixo produzido, esta ação é acordada previamente com os turistas, que geralmente estão de acordo com esta medida.

As comunidades Bananal, Nova Esperança e Boca da Mata, podem ser consideradas como um destino turístico indígena emergente no Estado de Roraima, sendo necessário para isso, a intervenção do poder público e órgãos indigenistas, cada um atuando em sua área, dando suporte ao planejamento, monitoramento da atividade, além de orientação na questão de acesso ao crédito de modo a possibilitar melhorias na infraestrutura. Com base no exposto, sugere-se que sejam priorizadas ações que visem transformar as iniciativas existentes em destinos de excelência em turismo indígena, criando assim, condições para que outras comunidades se inspirem nesses modelos. Como sugestão para estudos futuros, considera-se relevante um estudo comparativo em outras comunidades indígenas, tanto no contexto nacional como internacional. Considera-se como limitação do estudo, que o instrumento de coleta utilizado (ainda que validado pela OMT), não seja específico para a realidade do turismo indígena no Brasil. Ideal seria que o instrumento fosse construído juntamente com as comunidades.

Por fim, espera-se que os achados desta pesquisa possam contribuir para melhor compreender essa atividade ainda pouco estudada do Brasil. Mas que representa um segmento emergen- 
te do turismo, que se configura como uma nova oportunidade para a consecução dos objetivos do desenvolvimento local sustentável.

\section{REFERÊNCIAS}

Brandao, C. N., Barbieri, J. C., Reyes Junior, E. (2011). O Campo de Estudo do Turismo Sustentável em Comunidades Indígenas. In: XIII Anais ENGEMA - Encontro Nacional sobre de Gestão Empresarial e Meio Ambiente. São Paulo.

Brasil. (2004). Ministério do Turismo. Programa de Regionalização do Turismo - Roteiros do Brasil: Diretrizes Políticas. Brasília: Ministério do Turismo.

Turismo. (2004). Ministério do Turismo. Segmentação do turismo: marcos conceituais. Brasília: Ministério do Turismo. (2007). Plano Nacional de Turismo 2007/2010 - Uma viagem de inclusão. Brasília: Ministério do . (2007). Ministério do Turismo. Programa de Regionalização do Turismo - Roteiros do Brasil: Introdução à Regionalização do Turismo. Brasília: Ministério do Turismo.

Buarque, S. C. (2002). Construindo o desenvolvimento local sustentável: Metodologia de planejamento. Rio de Janeiro, Garamond.

Butler, R.; Hinch, T. (2006). Tourism and indigenous people: issues and implications. Oxford. Burlington: Elsevier.

Butler, R. W. (1999). Sustainable tourism: A state-of-the-art review. Tourism Geographies: An International Journal of Tourism Space, Place and Environment. 1(1), 7-25.

Butts, T.; Singh, S. (2010). Sustainable tourism as a tool for conservation and protection of the Amazon rainforest in Guyana? Sustainable tourism. 2(2), 173-185.

Byrd, E. T. (2007). Stakeholders in sustainable tourism development and their roles. Tourism Review. 62(2).

Ciegis, R. et al. (2009). Theoretical Reasoning of the Use of Indicators and Indices for Sustainable Development Assessment. 2009. The Economic Conditions of Enterprise Functioning. 3.

CMMAD - Comissão Mundial sobre Meio Ambiente e Desenvolvimento. (1991). Nosso futuro comum. 2 ed. Tradução de Our common future. 1a ed. 1988. Rio de Janeiro: Fundação Getulio Vargas.

CNUMAD. Conferência das Nações Unidas para o Meio Ambiente e Desenvolvimento. Rio de Janeiro, 3-14 jun. 1992. Disponível em: http://www.un.org/geninfo/bp/enviro.html, acessado em 23 de janeiro de 2012.

CSD - Commission on Sustainable Development. Tourism and sustainable development sustainable tourism: a non-governmental organization perspective. Seventh Session 19-30 April 1999, New York. Disponível em: http://www.gdrc.org/uem/eco-tour/ngo4.pdf. Acesso em 15 de dezembro de 2011. 
Hair JR, J.F. (2005). Fundamentos de métodos de pesquisam em administração. Tradução: Lane Belon Ribeiro. Porto Alegre: Bookman.

Hinch, T.; BUTLER, R. (1996). Indigenous tourism: A common ground for discussion. London: International Thomson, Business Press.

Hunter, C. (2002). Sustainable tourism and the touristic ecological footprint. Environment, Development and Sustainability. 4, 7-20.

Hunter, C e GREEN, H. (1995). Tourism and the environment: a sustainable relationship? London; New York: Routledge.

IBGE - Instituto Brasileiro de Geografia e Estatística - IBGE. (2008). Indicadores de desenvolvimento sustentável. Rio de Janeiro. IBGE. Censo 2010. Disponível em:

http://www.ibge.gov.br/estadosat/temas.php?sigla=rr\&tema=resultuniverso_censo2010.

IPEA. (1996). Cadernos Comunidade Solidária, v.6. jun.1998. Brasília: IPEA.

Jayawardena, C. et al. (1998). Sustainable tourism development in Niagara Discussions, theories, projects and insights. International Journal of Contemporary Hospitality Management. 20(3), 258-277.

Johnston, J.; Tyrrel, J. (2007). Management exercises and trainer's note in sustainable tourism and dynamics. International Journal of Culture, Tourism and Hospitality Research. 1(4).

Levine, D.M.; Berenson, M.L.; Stephan, D. (2000). Estatística: teoria e aplicações usando o Microsoft Excel em português. Rio de Janeiro: LTC.

Lohmann, G; Netto, A.P. (2008). Teoria do turismo: conceitos, modelos e sistemas. São Paulo: Aleph.

Mondadori, M. G.; Ladeira, W. J. (2007). Validação de um instrumento quantitativo em pesquisa de empreendedorismo e inovação: um estudo no contexto dos recursos tangíveis e intangíveis. Anais do Encontro da Anpad, XXXI, 2007, Rio de Janeiro: Enanpad, Setembro.

Meulman, J. J.; Heiser, W. J. (2005). SPSS Categories 14.0. SPSS Inc. Chicago.

Murphy, P.E.; Murphy, A.E. (2004). Strategic management for tourism communities: bridging the gaps. Aspects of tourism. Channel View Publications.

Nizic, M.K. et al. (2010). Challenges to sustainable development in island tourism. South East European Journal of Econmics and Business. 5(2).

Organização Mundial do Turismo - OMT (2000). Workshop on Indicators for the Sustainable Development of Tourism. Final Report. World Tourism Organization.

Organização Mundial do Turismo - OMT. (2001). Programa de Municipalização do Turismo - Manual de municipalização do turismo. 2.ed. Brasília: EMBRATUR; OMT.

Organização Mundial do Turismo - OMT. (2001). Introdução ao turismo. São Paulo: Roca, 2001. 
Organização Mundial do Turismo OMT -. (2005). Tourism highlights, 2005 edition. WTO: Madrid. Disponível em: <http://www.world-tourism.org/facts/wtb.html>. Acesso em 28 de agosto de 2009.

Pontes, A. C. F. (2005). Análise de variância multivariada com a utilização de testes nãoparamétricos e componentes principais baseados em matrizes de postos. Tese (Doutorado) - Escola Superior de Agricultura Luiz de Queiroz, Universidade de São Paulo, Piracicaba. Disponível em:

<http://www.teses.usp.br/teses/disponiveis/11/11134/tde09082005123633/publico/AntonioPontes.pdf>. Acesso em: 15/07/2012.

Reid, S.; Ruhanen, L., Davidson, M. (2010). Legal basis for state and territory tourism planning. National Library of Australia.

Sinclair, D. (2003). Developing indigenous tourism: Challenges for the Guianas. International Journal of Contemporary Hospitality Management.15(3), 402-407.

Smith, T. (2006). Welfare, enterprise, and aboriginal community: the case of the western australian kimberley region. Australian Economic History Review. 46(3).

Swarbrooke, J. (2000). Turismo sustentável: conceitos e impacto ambiental. Vol.1. Tradução de Sustainable tourism management. Oxon: CABI. São Paulo: Aleph, 2000.

UNITED NATIONS (UN). (2001). Indicators of Sustainable Development: Guidelines and Methodologies 2001. UN: New York.

UNWTO. (2005). Making tourism more sustainable: a guide for policy makers. United Nations Environment Programme and World Tourism Organization. France; Spain.

Weaver, D. (2010). Indigenous tourism stages and their implications for sustainability. Journal of Sustainable Tourism. 18(1), 43-60. Jan.

WTO. (2001). Final report -Workshop on Sustainable Tourism Indicators for the Islands of the Mediterranean Kukljica, Island of Ugljan, Croatia 21-23 March.

WTO. (2004). Indicators of Sustainable Development for Tourism Destinations: a Guidebook. World Tourism Organization, Madrid, Spain.

WTO. (2005). Making tourism more sustainable: a guide for policy makers. United Nations Environment Programme and World Tourism Organization. France; Spain.

Yin. R. K. (2010). Estudo de caso: planejamento e métodos. 3 ed. Porto Alegre: Bookman.

Zeppel, H. (2006). Indigenous ecotourism: sustainable development and management. CABI.

Artigo recebido em: 15/01/2014. Artigo aprovado em: 25/11/2015. 